\title{
APPLICATION OF CARBOXYMETHYLATED CAROB BEAN GUM AS ECO-FRIENDLY WATER BASED DRILLING FLUIDS ADDITIVE
}

\author{
Wei-Chao DU, ${ }^{\mathrm{a}, \mathrm{b},{ }^{*}}$ Xiang-Yun WANG, ${ }^{\mathrm{a}}$ Liu-Xiang KANG, ${ }^{\mathrm{c}}$ Yong SU, ${ }^{\mathrm{c}}$ Xian-Bin HUANG, ${ }^{\mathrm{b}}$ \\ Gang CHEN $^{\mathrm{a}, \mathrm{d}}$ and Jie ZHANG ${ }^{\mathrm{a}}$ \\ ${ }^{\text {a }}$ Shaanxi Province Key Laboratory of Environmental Pollution Control and Reservoir Protection Technology of Oilfields, \\ Xi'an Shiyou University, Xi' an 710065, China \\ ${ }^{\mathrm{b}}$ Shandong Key Laboratory of Oilfield Chemistry, China University of Petroleum (East China), Qingdao 266580, China \\ ${ }^{c}$ Changqing Oilfield Company Oil Production No.11, CNPC, Qingyang 420100, China \\ ${ }^{\mathrm{d}}$ State Key Laboratory of Petroleum Pollution Control, CNPC Research Institute of Safety and Environmental Technology, \\ Beijing, 102206, China
}

Excessive exploitation of non-renewable energy and environmental damage have forced people's scientific research turn to in-exhaustible nature plants. In this work, carob bean gum (CBG) was modified using sodium chloroacetate as the modifier to enhance its solubility and efficiency in water based drilling fluids. The modification conditions were discussed through single factor test and screened as follows: the mass ratio of sodium chloroacetate to $\mathrm{CBG}$ was $20.0 \mathrm{~g} / 100 \mathrm{~g}$ with $\mathrm{pH} 12$ at the temperature of $50^{\circ} \mathrm{C}$ for $6 \mathrm{~h}$. The rheological property and filtration loss of carboxymethylated carob bean gum (CCBG) treated drilling fluids were tested, which demonstrated more excellent rheological property and lower filtration loss than that of $\mathrm{CBG}$. The inhibitive property of CCBG was evaluated by using Na-Bentonite (Na-MMT) -swelling tests and mud ball immersing tests, which showed that CCBG performed a high inhibitive and anti-caving capacities in water-based drilling fluids.

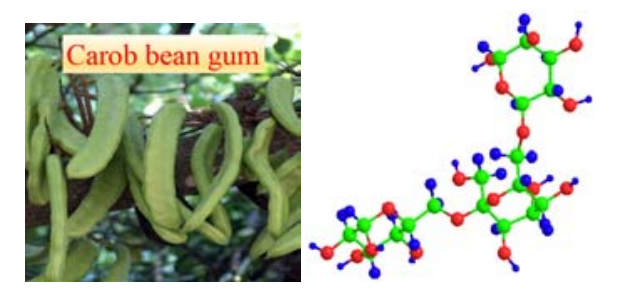

\section{INTRODUCTION}

Drilling fluids is the core technology of drilling engineering and called the "blood" of drilling. It is a complex colloid-suspension multi-stage dispersion system formed by clay particles and various chemical agents. ${ }^{1-3}$ During the drilling process, drilling fluids plays the role of carrying cuttings, maintaining the stability of borehole wall, balancing formation pressure, cooling drilling tools, and transmitting water power. ${ }^{4}$ It is the key technology to ensure well formation, oil and gas reservoir discovery and to prevent collapse, stuck, leaking, blowout and other safety accidents during drilling. Due to the increasing emphasis on environmental protection issues, new and more stringent requirements are imposed on the environmental performance of drilling fluids, which require that drilling fluids should be nontoxic and degradable. Compared with oil-based drilling fluids, water-based drilling fluids have significant advantages in environmental protection and low cost, statistics show that $80 \%$ of drilling projects are using water-based drilling fluids. Therefore, the development of water-based drilling fluids that meet the needs of drilling engineering technology and environmental protection through the development of environmentally-friendly drilling fluids additive has become one of the important directions of current drilling fluid technology research and one of the hot spots in drilling fluid research. ${ }^{5-7}$

\footnotetext{
${ }^{*}$ Corresponding author: duweichao@xsyu.edu.cn
} 
Commonly, water-based drilling fluids for oil field application need some water-soluble polymers to enhance its viscosity, suppress the hydration and swelling of clay or shale and control the rheological property of the drilling fluids. ${ }^{8}$ Both natural and synthetic water-soluble polymers have been widely used in such water-based drilling fluids, among which natural polysaccharides are preferred to synthetic materials due to their non-toxicity, low cost and biodegradable ability. ${ }^{9-11}$ Plants are extremely common in nature, with a broad source and is being promoted by the chemist. Thereby, the plant-derived drilling fluids additives have increasingly favored by oil field workers. In fact, a wide range of natural polysaccharides has been used as eco-friendly drilling fluids additives with nice viscosity-increasing property and compatibility with other materials. ${ }^{12-14}$ In addition, as an important environmental protection additive for water based drilling fluids, nanoparticles show a good application prospect in petroleum industry, the benefits of nanofluids in water based drilling fluids include improvement of fluids rheological properties, reductions in filtration loss and friction coefficient, increase of the rate of heat transfer, shale stability improvement, and inhibition of gas hydrate formation. ${ }^{15-20}$

Tree gums are natural polysaccharides consisted with multiple monosaccharides such as arabinose, galactose, glucose, mannose, xylose and uronic acids. Carob bean gum (CBG), Prunus persica (L.) Batsch, is a branched acidic heteropolysaccharide extracted from the secretion of a rosaceae plant (Figure 1). The basic units are aldopentose and aldohexose, which compose L-arbinose (42.8\%), D-galactose (35.7\%), D-xylose (14.3\%) and Dsedoheptulose (7.2\%). The CBG has been used as a drilling fluids additive with higher temperature resistance, shear stability and anti-biodegradation compared with modified starch. ${ }^{21}$
However, there are some problems during the use of CBG in drilling fluids, which include the low clay hydration inhibition, low solubility, weak thickening, viscosity dropping during storage and the possibility of microbial contamination., 9-11 Chemical modification of gums is a usual way to enhance the solubility and thickening. The aim of this work is to investigate the chemical modification of CBG by carboxymethylation under different reaction conditions and evaluate its application as an environmentally friendly drillingfluids additive.

\section{EXPERIMENTAL}

\section{Materials}

CBG sample was purchased from Changzhou Shuangjia Chemical Engineering Company. Sodium chloroacetate and other chemicals were obtained from Tianjing Chemical Reagent Co., Ltd, China. Na-MMT was obtained from Xinjiang Xiazi Street Bentonite Co., Ltd., and the chemical composition (wt.\%) is: $\mathrm{SiO}_{2}$ 60.54, $\mathrm{Al}_{2} \mathrm{O}_{3}$ 23.93, $\mathrm{FeO}$ 0.23, $\mathrm{Fe}_{2} \mathrm{O}_{3} 4.29, \mathrm{MgO} 2.56, \mathrm{CaO} 2.78, \mathrm{~K}_{2} \mathrm{O} 1.45$ and others 4.22.

\section{Carboxymethylation of CBG}

The carboxymethylation reaction of $\mathrm{CBG}$ is shown in Scheme1. The following procedure was adopted in carrying out the reactions: $\mathrm{CBG}, \mathrm{NaOH}$ and water were mixed and stirred at certain temperature until a homogeneous gel was formed. Sodium chloroacetate was then added. The mixture was heated to a certain temperature for $6 \mathrm{~h}$. After the completion of reaction, the gel was cooled to room temperature and the $\mathrm{pH}$ was adjusted to 7 using dilute acetic acid. The solvent was evaporated under in vacuum, and the residue was dried under $80^{\circ} \mathrm{C}$ to give the modified $\mathrm{CBG}$ (named as CCBG).

\section{Differential scanning calorimetry (DSC) characterizations}

The carboxymethylation of CBG was characterized by DSC (METTLER TOLEDO, Switzerland), the tested samples were $0.5 \mathrm{~g}$ and the heating rate was $20^{\circ} \mathrm{C} / \mathrm{min}$ from $20^{\circ} \mathrm{C}$ to $250^{\circ} \mathrm{C}$.
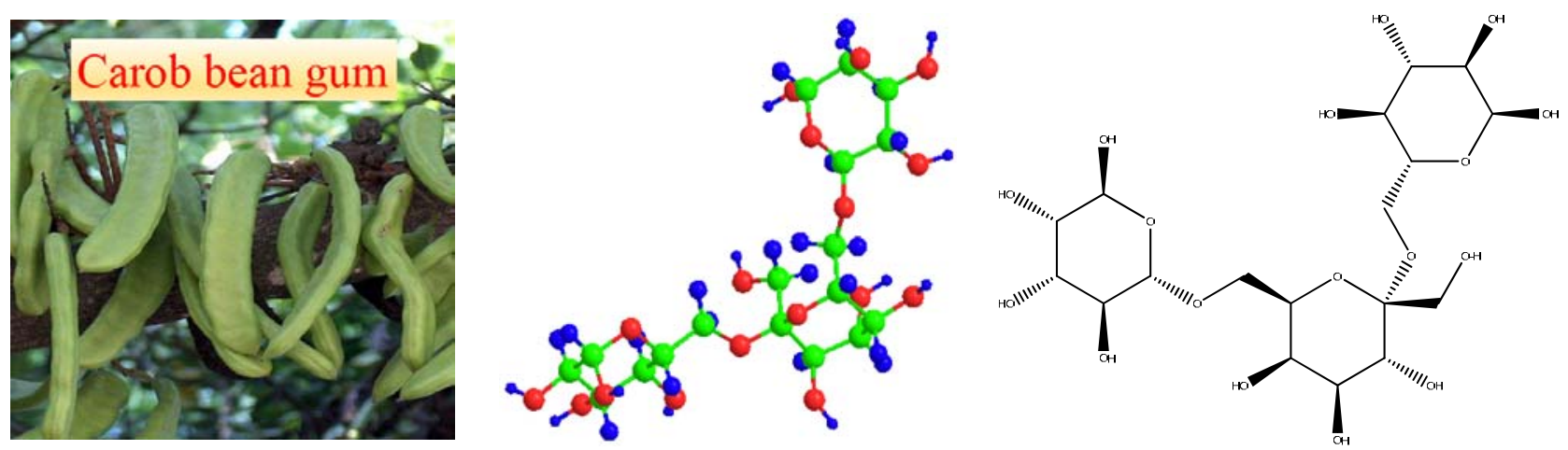

Fig. 1 - Carob bean gum: left (carob bean); middle (3D model) and right (molecule structure). 


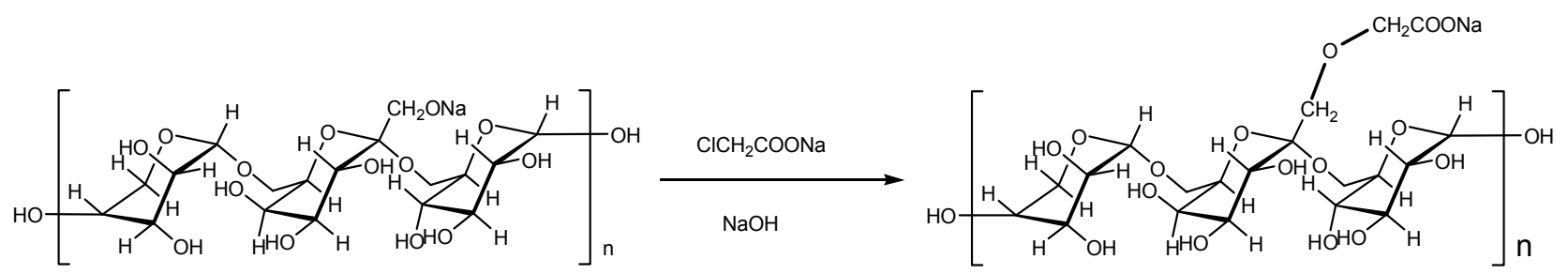

Scheme 1 - Carboxymethylation of CBG with sodium chloroacetate.

\section{Swelling inhibition experiments}

As the hydration expansion of shale is mainly caused by the expansive Na-MMT in the shale composition, the evaluation of a shale inhibitor generally by using Na-MMT. The hydration swelling of Na-MMT was tested by a NP-01 shale swelling instrument (Haitongda, Co., Ltd., Qingdao, China), in accordance with Chinese Petroleum and Natural Gas Industry Standards SY/T6335-1997. The swelling rate, $\% \mathrm{SR}$, was calculated as follows:

$$
\% \mathrm{SR}=(\Delta \mathrm{H} / \mathrm{H} 0) \times 100
$$

where $\mathrm{H} 0$ is the thickness of the artificial core and $\Delta \mathrm{H}$ is the increased in thickness. The smaller the \%SR was, the stronger the anti-swell ability of the additive was.

In mud ball immersing tests, Na-MMT $(10 \mathrm{~g})$ was used to make a mud ball and the mud ball was immersed in $100 \mathrm{~mL}$ distilled water or other aqueous solutions for $36 \mathrm{~h}$.

\section{Drilling fluids properties evaluations}

The preparation procedure of $4 \%(\mathrm{~m} / \mathrm{m})$ Na-MMT based drilling fluids was as follows: Accurately measure $1000 \mathrm{~mL}$ distilled water into a porcelain cup, and then added $40 \mathrm{~g} \mathrm{Na}-$ MMT, stirred it at high speed for 2 hours, and then placed it at room temperature for 24 hours for use. When drilling fluids experiments were conducted, $4 \%(\mathrm{~m} / \mathrm{m})$ Na-MMT was dispersed in $350 \mathrm{~mL}$ inhibitor solutions. After stirred for $20 \mathrm{~min}$ and aged it for $16 \mathrm{~h}$ at a certain temperature, then the rheological properties and filtration property of the fluids samples were measured using a model ZNN-D6S viscometer (Hai tongda, Co., Ltd., Qingdao, China), including Apparent Viscosity (AV), Plastic Viscosity (PV), Yield Point (YP), Dynamic Plastic ratio (YP/PV), API filtration (FL) and friction coefficient (tg). The AV, PV and YP were calculated from 300 and $600 \mathrm{rpm}$ readings using the following formulas from API standard of drilling fluids (API RP 13B-1-2009):

$$
\begin{gathered}
\mathrm{AV}=\phi_{600} / 2(\mathrm{mPa} \cdot \mathrm{s}) \\
\mathrm{PV}=\phi_{600}-\phi_{300}(\mathrm{mPa} \cdot \mathrm{s}) \\
\mathrm{YP}=\left(\phi_{300}-\mathrm{PV}\right) / 2\left(\mathrm{~N} / \mathrm{m}^{2}\right)
\end{gathered}
$$

\section{RESULTS AND DISCUSSION}

\section{Characterization}

The endothermic peaks in DSC curves could reveal the phase transition of the gums, and the carboxymethylated $\mathrm{CBG}$ and $\mathrm{CCBG}$ were characterized by DSC as shown in Figure 2. The transition peak temperature of $\mathrm{CBG}$ has changed remarkably from $158.3^{\circ} \mathrm{C}$ to $145.8^{\circ} \mathrm{C}$ after the modification by chloroacetic acid, which confirmed the successful carboxymethylation of CBG. The reasons may be due to the increased ether bonds formed by the hydroxyl groups and chloroacetate of them, which can weaken the intermolecular hydrogen bonding and makes the phase transition of the gum easier.

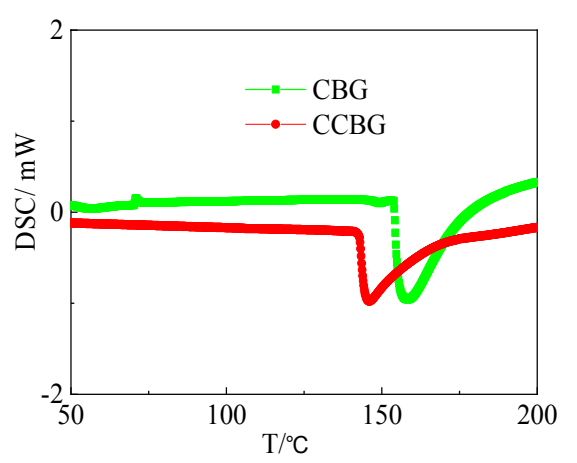

Fig. 2 - The DSC curves of CBG and CCBG.

\section{Reaction condition optimizations of CCBG}

\subsection{Effect of sodium chloroacetate}

Sodium chloroacetate is an efficient carboxymethyl agent for many proteoglycans and gums. $\mathrm{pH}$ and reaction temperature are set at 7 and $60^{\circ} \mathrm{C}$, respectively, and the effect of mass ratio of sodium chloroacetate to $\mathrm{CBG}$ sodium was studied by varying the mass ratio of sodium chloroacetate to CBG from $4.00 \mathrm{~g} / 100 \mathrm{~g}$ to $60.0 \mathrm{~g} / 100 \mathrm{~g}$. Then, the rheological properties of drilling fluids treated by different products were evaluated, and the results were summarized in Table 1.

It showed that there was an obvious increasing in the AV and the FL decreased with the mass ratio up to $20.0 \mathrm{~g} / 100 \mathrm{~g}$, and the optimized mass ratio of sodium chloroacetate to $\mathrm{CBG}$ was selected as $20.0 \mathrm{~g} / 100 \mathrm{~g}$. The results may be that after the carboxymethylation modified $\mathrm{CBG}$ has a better water solubility. At this time, the molecular chain of CCBG became more entangled with each other, which can increased the viscosity of drilling fluids. 
Theoretically, the addition amount increasing of carboxymethylation reagent was conducive to the carboxymethylation reaction, which can greatly improve the reaction rate of CCBG. However, when the mass ratio exceeded $20.0 \mathrm{~g} / 100 \mathrm{~g}$ the $\mathrm{AV}$ has reduced, the reason may possibly due to the increase of side reactions reducing the effective utilization of raw materials.

\subsection{Effect of $p H$}

The mass ratio of sodium chloroacetate to $\mathrm{CBG}$ and reaction temperature was set at $20.0 \mathrm{~g} / 100 \mathrm{~g}$ and $60^{\circ} \mathrm{C}$, respectively, the effect of $\mathrm{pH}$ (from 3 to 13) was studied, and the rheological properties of drilling fluids treated by different products were tested.

As shown in Table 2, a better performances in the rheological property was presented with an increment of $\mathrm{pH}$, and the rheological property has reached to the niced at the $\mathrm{pH}$ of 12 . When the $\mathrm{pH}$ exceeded 12, the performance of the drilling fluids have decreased slightly. The reasons may be that the carboxymethylation process was affected by $\mathrm{pH}$. There are two competitive reactions in the carboxymethylation process. Firstly, there was a typical substitution of CBG and sodium chloroacetate in the presence of sodium hydroxide as shown in Eq. (1).

And sodium glycolate may be produced in the second reaction as shown in Eq. (2).

$$
\begin{gathered}
\mathrm{CBG}-\mathrm{OH}+\mathrm{ClCH}_{2} \mathrm{COONa} \longrightarrow \mathrm{CBG}-\mathrm{O}-\mathrm{CH}_{2} \mathrm{COONa}+\mathrm{NaCl}+\mathrm{H}_{2} \mathrm{O} \\
\mathrm{NaOH}+\mathrm{ClCH}_{2} \mathrm{COONa} \longrightarrow \mathrm{HOCH}_{2} \mathrm{COONa}+\mathrm{NaCl}
\end{gathered}
$$

Table 1

\begin{tabular}{|c|c|c|c|c|c|}
\hline Sample & $\mathrm{Mg} / \mathbf{1 0 0 g}^{\mathrm{a}}$ & $\mathbf{A V} / \mathbf{m P a} \cdot \mathbf{s}$ & $\mathbf{P V} / \mathbf{m P a} \cdot \mathbf{s}$ & $\mathbf{Y P} / \mathbf{P a}$ & $\mathbf{F L} / \mathbf{m L}$ \\
\hline \multirow[t]{3}{*}{ Based drilling fluids } & 0 & 4.5 & 3.0 & 1.5 & 19.4 \\
\hline & 4.0 & 6.8 & 3.5 & 3.3 & 17.4 \\
\hline & 12.0 & 7.8 & 4.5 & 3.3 & 15.8 \\
\hline \multirow{3}{*}{$\begin{array}{l}\text { Based drilling fluids }+ \\
0.5 \% \mathrm{CCBG}^{\mathrm{b}}\end{array}$} & 20.0 & 8.8 & 5.5 & 3.3 & 15.0 \\
\hline & 40.0 & 6.5 & 3.0 & 3.6 & 18.0 \\
\hline & 60.0 & 6.8 & 3.5 & 3.3 & 17.6 \\
\hline
\end{tabular}

Effect of the mass ratio on performance of CCBG treated drilling fluids

NOTE: ${ }^{\mathrm{a}} \mathrm{M}$ means the mass ratio of sodium chloroacetate to $100 \mathrm{~g} \mathrm{CBG} ;{ }^{\mathrm{b}}$ Unless otherwise specified, all percentage in the table shall be the mass fraction.

Table 2

\begin{tabular}{|c|c|c|c|c|c|}
\hline Sample & $\mathbf{p H}$ & $\mathbf{A V} / \mathbf{m P a} \cdot \mathbf{s}$ & $\mathbf{P V} / \mathbf{m P a} \cdot \mathbf{s}$ & $\mathbf{Y P} / \mathbf{P a}$ & FL/mL \\
\hline Based drilling fluids & & 3.8 & 2.0 & 1.8 & 27.8 \\
\hline \multirow{6}{*}{ Based drilling fluids $+0.5 \% \mathrm{CCBG}$} & 3 & 5.3 & 4.0 & 2.3 & 17.5 \\
\hline & 4 & 6.0 & 4.0 & 5.1 & 16.0 \\
\hline & 8 & 8.3 & 5.0 & 3.6 & 14.4 \\
\hline & 10 & 10.0 & 6.5 & 3.6 & 14.4 \\
\hline & 12 & 10.3 & 5.5 & 4.9 & 14.2 \\
\hline & 13 & 9.8 & 5.5 & 4.3 & 16.0 \\
\hline
\end{tabular}

Effect of $\mathrm{pH}$ on performance of CCBG treated drilling fluids 
When the $\mathrm{pH}$ exceed 12, a large amount of sodium glycolate was produced as a by-product, and this process consumes a large amount of raw materials, thereby reducing the quality of the product. ${ }^{10}$

\subsection{Effect of reaction temperature}

The mass ratio of sodium chloroacetate to $\mathrm{CBG}$ and $\mathrm{pH}$ was set at $20.0 \mathrm{~g} / 100 \mathrm{~g}$ and 12 respectively, and the effect of temperature on the performance of CCBG in the drilling fluids has been carried out at five reaction temperatures, as shown in Table 3.

When the reaction temperature was below $50{ }^{\circ} \mathrm{C}$, the $\mathrm{AV}$ of the drilling fluids increased with the increasing of temperature, and perfect performance of CCMG was obtained at $50{ }^{\circ} \mathrm{C}$. The increasing of temperature has made the carboxymethylation of CBG easier, and was conducive to the smooth expansion of the product in aqueous solution, which have led to the increase of $\mathrm{AV} .{ }^{22-24}$ When the reaction temperature exceeded $50{ }^{\circ} \mathrm{C}$, the increasing of temperature may lead to the degradation of $\mathrm{CBG}$ and the occurrence of side reactions, thus the performances of $\mathrm{CCBG}$ have decreased accordingly.

\section{Performance of CCBG in water-based drilling fluids}

\subsection{Rheological properties}

To evaluate the performance of CCBG as a drilling fluids additive, the rheological properties of based drilling fluids, CBG treated drilling fluids and CCBG treated drilling fluids were tested according to the American Petroleum Institute (API) specifications, and the results are shown in Table 4.

Table 3

Effect of reaction temperature on performance of CCBG treated drilling fluids

\begin{tabular}{|c|c|c|c|c|c|}
\hline Sample & Temperature $/{ }^{\circ} \mathrm{C}$ & $\mathbf{A V} / \mathbf{m P a} \cdot \mathbf{s}$ & $\mathbf{P V} / \mathbf{m P a} \cdot \mathbf{s}$ & $\mathbf{Y P} / \mathbf{P a}$ & FL/mL \\
\hline \multirow[t]{3}{*}{ Based drilling fluids } & 30 & 3.8 & 2.0 & 1.8 & 27.8 \\
\hline & 30 & 8.3 & 5.0 & 3.3 & 15.4 \\
\hline & 50 & 11.6 & 7.5 & 4.2 & 13.2 \\
\hline \multirow{3}{*}{$\begin{array}{l}\text { Based drilling fluids } \\
\quad+0.5 \% \text { CCBG }\end{array}$} & 60 & 9.3 & 5.5 & 3.8 & 14.0 \\
\hline & 70 & 10.0 & 6.0 & 4.1 & 14.2 \\
\hline & 80 & 10.0 & 5.0 & 5.1 & 14.5 \\
\hline
\end{tabular}

Table 4

The rheological behaviors of different drilling fluids

\begin{tabular}{cccccc}
\hline Drilling fluids & Concentration/wt \% & AV/mPa·s & PV/mPa·s & YP/Pa & FL/mL \\
\hline Based drilling fluids & - & 3.8 & 2.0 & 1.8 & 27.8 \\
CBG treated drilling fluids & 0.5 & 4.5 & 3.0 & 1.5 & 19.4 \\
\multirow{2}{*}{ CCBG treated drilling } & 1 & 6.3 & 4.5 & 1.8 & 14.0 \\
fluids & 0.5 & 8.8 & 6.3 & 2.5 & 12.2 \\
\hline
\end{tabular}

It shows that CCBG has an obvious advantage as viscosifying improver agent in drilling fluids. Compared with CBG, CCBG remarkably increased the viscosity of based drilling fluids with a percentage of $183.3 \%$, and have reduced the filtration loss with $32.9 \%$. As we know, the zeta potential of clay determines the rheological properties and fluids loss volume of drilling fluids, and the zeta potential of may be affected by the diffusion electric double layer of the clay particles and the medium of drilling fluids. ${ }^{25}$ The ionized molecular chain of CCBG could produce the carboxylic acid anion, which have enhanced the zeta potential and thickened the hydration shell on 
the clay surface, thus preventing the agglomeration of clay particles. In addition, the network structure formed by CCBG molecular chain also increased the viscosity of drilling fluids and thus to reduce the filtration volume of drilling fluids.

\subsection{Clay-swelling Inhibition}

Under normal temperature and pressure, the inhibition performance of Na-MMT swelling was evaluated by linear swelling tests and mud ball immersion tests. The linear swelling rate results are shown in Figure 3. As we can see that there is no significant differences between $\mathrm{CBG}$ and water, which means that the inhibition property of $\mathrm{CBG}$ was very poor. However, the swelling rate of $0.5 \%$ CCBG solutions in 8 hours was only $34.2 \%$, which was significantly lower than that of $0.5 \% \mathrm{CBG}$ solutions, even more effective than that of $10 \%$ sodium silicate solution.

The mud ball immersing tests provide a more intuitive way to describe the inhibitive property of a drilling fluids and the inhibitive ability of CCBG and $\mathrm{CBG}$ was studied, respectively. Figure 4 shows the status of the mud balls after immersed in water, $1 \% \mathrm{CCBG}$ and $1 \% \mathrm{CBG}$ for 36 hours, results showed that the mud ball immersed in water have swelled obviously, and cracked was appeared on the surface of the ball. The similar status was found in CBG solution. The mud ball immersed in CCBG solution swells slightly and the surface is very smooth with no cracks on the surface.

It is clear that CCBG has the significantly stronger shale -swelling inhibition in the waterbased drilling fluids comparing with $\mathrm{CBG}$. The reasons for this phenomenon may be that: the water solubility of CCBG increases the viscosity of drilling fluids, and the intermolecular force formed by the silanol groups on the shale surface and the carboxyl group of CCBG have caused a layer of hydrated shell on the Na-MMT surface, which will prevent water penetrating into the mud ball, thus inhibiting the hydration and dispersion of shale. ${ }^{26,27}$

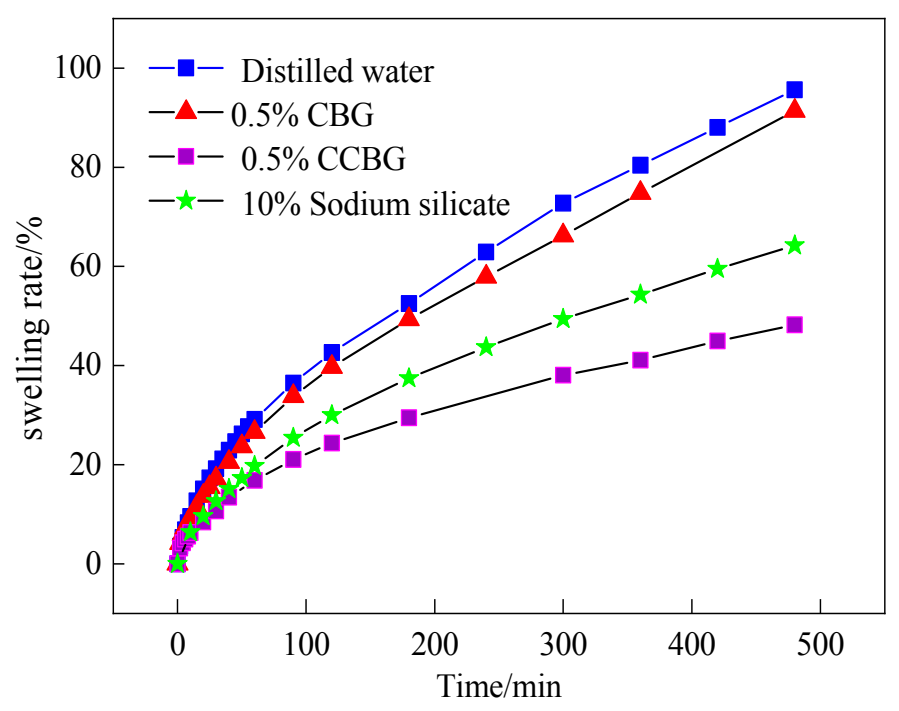

Fig. 3 - The linear swelling rate of clay in different solutions.
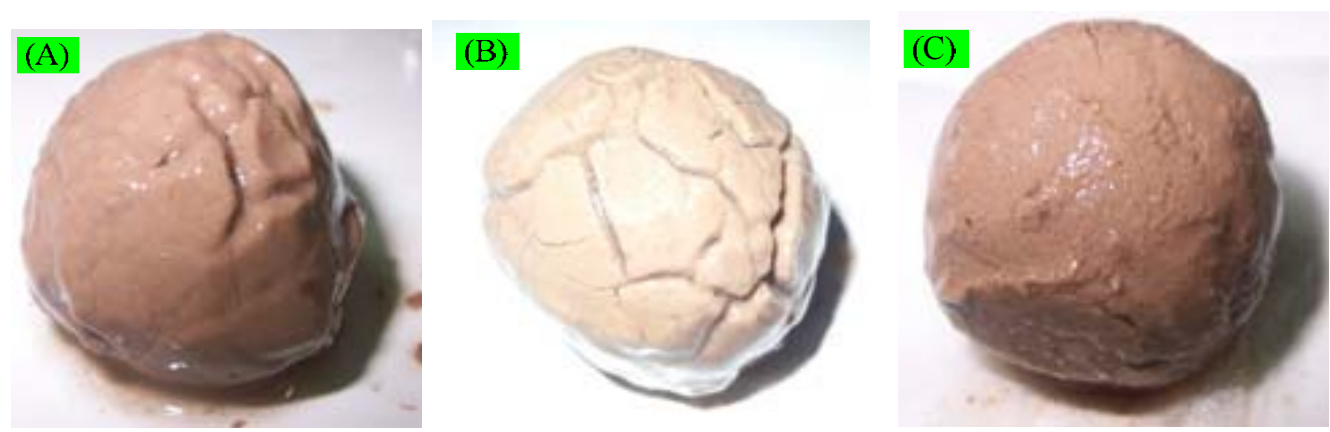

Fig. 4 - The status of mud balls immersed in different fluids for $36 \mathrm{~h}$, (A) the mud ball immersed into water, (B) mud balls immersed into $0.5 \%$ wt CBG solution and (C) mud balls immersed into $0.5 \% \mathrm{wt}$ CCBG solutions. 


\section{CONCLUSIONS}

In order to develop environmentally friendly drilling fluids additive with excellent performance, carboxymethylation of CBG was carried out in this paper to prepare CCBG. The optimal modification conditions of CCBG were studied, and the results showed that at a reaction temperature at $50{ }^{\circ} \mathrm{C}$, the mass ratio of sodium chloroacetate was $20 \mathrm{~g} / 100 \mathrm{~g}$, the $\mathrm{pH}$ value was 12 , the rheological and filtration properties of CCBG has been effectively improved. Na-MMT swelling tests and mud ball immersion tests have proven that CCBG has a significant inhibitory effect on Na-MMT swelling in water-based drilling fluids. The results show that CCBG can be used as an environmentally friendly drilling fluids additive in oilfield.

Acknowledgements. The authors would like to thank"the Opening Fund of Shandong Key Laboratory of Oilfield Chemistry", "the Fundamental Research Funds for the Central Universities (19CX05006A)"and "Natural Science Basic Research Program of Shaanxi (Program No. 2020JQ-785 )" for financial support.

\section{REFERENCES}

1. W. C. Du, X. Y. Wang, G. Chen, J. Zhang and M. Slaný, Minerals., 2020, 10, 128.

2. E. Kusrini, F. Oktavianto, A. Usman, D. P. Mawarni and M. I. Alhamid, Appl. Surf. Sci., 2020, 506, 145005.

3. C. Vipulanandan and A. Mohammed, J. Petrol. Sci. Eng., 2020, 189, 107029.

4. W. C. Du, M. Slaný, X. Y. Wang, G. Chen and J. Zhang, Polymers., 2020, 12, 708.

5. R. J. Zhang, L, Gao, W. C. Du, W. M. Hu, W. G. Duan and X. F. Gu, Molecules., 2019, 24, 4331.
6. R. L. Anderson, I. Ratcliffe, H. C. Greenwell, P. A. Williams, S. Cliffe and P. V. Coveney, Earth-Sci. Rev, 2010, 98, 201.

7. R. Gholami, H. Elochukwu, N. Fakhari and M. Sarmadivaleh, Earth-Sci. Rev., 2018, 177, 2

8. R. Jain and V. Mahto, J. Petrol. Sci. Eng., 2015, 133, 612.

9. G. Chen, J. Yan, L. L. Li, J. Zhang, X. F. Gu, and H. Song, Appl. Clay. Sci., 2017, 138: 12-16.

10. G. Chen, L. Gao, K. Dong, Y. Sun, W. M. Hu and W. C. Du, J. biobased. Mater. Bio., 2019, 13, 778.

11. J. Zhang, W. M. Hu, L. Zhang, T. H. Li, D. Cai and G. Chen, Adsorpt Sci Technol., 2019, 37, 49-60.

12. M. Graeme, Prog. Polym. Sci., 2011, 36, 218.

13. A. Hebesh and M. I. Khalil, Starch/Staerke., 1998, 40, 147.

14. A. Rana, M. K. Arfaj and T. A. Saleh, Fuel., 2019, 247, 237.

15. J. T. Shakib, V. Kanani, and P. Pourafshary., J. Petrol. Sci. Eng., 2016, 138, 257.

16. H. Ş. Aybar, M. Sharifpur, M. R Azizian, M. Mehrabi and J. P. Meyer, Heat Transfer Een., 2015, 36, 1085.

17. J. Abdo and M. D. Haneef, Appl. Clay. Sci., 2013, 86, 76.

18. L. Salehnezhad, A. Heydari and M Fattahi, J Mol. Liq., 2019, 276, 417.

19. R. Rafati, S. R. Smith, A. S. Haddad, R. Novara and H. Hamidi, J. Petrol. Sci. Eng., 2018, 161, 61.

20. K. Anoop, R. Sadr, R. Yrac and M. Amani, Powder Technol., 2019, 342, 585.

21. J. L. Ren, R.C. Sun and F. Peng, Polym. Degrad. Stabil., 2008, 93, 786.

22. G. T. Teixeira, R. F. Lomba, A. D. Francisco, J. F. da Silva and R. S. Nascimento, J. Appl. Polym. Sci., 2014, 131, 40384 .

23. M Manea, Rev. Roum. Chim., 2012, 57, 197.

24. V. Rana, P. Rai, A. K. Tiwary, R. S. Singh, J. F. Kennedy and C. J. Knill, Carbohydr. Polym., 2011, 83, 1031.

25. G. Xie, Y. R. Xiao, M. Y. Deng, Q. Zhang, D. C. Huang, L. F. Jiang, Y. Yang and P. Y. Luo, Energ Fuel., 2019, 33, 9067.

26. S. R. Shadizadeh, A. Moslemizadeh and A. S. Dezaki, Appl. Clay Sci., 2015, 118, 74-86.

27. H. M. Ahmed, M. S. Kamal and M. Al-Harthi; Fuel., 2019, $251,187-217$. 
